* Mestre em Ecologia, Ambiente e Sociedade pela Universidade Federal dos Vales do Jequitinhonha e Mucuri - UFVJM. Especialista em Negociação Coletiva pela Escola de Administração da Universidade Federal do Rio Grande do Sul - UFRGS. Graduado em administração pela Fundação Educacional Nordeste Mineiro - FENORD E-mail: adm.guilherme@outlook.om

** Doutor em Engenharia Agrícola pelo programa de pósgraduação da Universidade Federal de Viçosa Mestre em Engenharia Agrícola pela Universidade Federal de Viçosa. Graduado em Agronomia pela Universidade Federal de Viçosa. Professor adjunto III e pesquisador da Universidade Federal dos Vales do Jequitinhonha e Mucuri, Campus do Mucuri, Teófilo Otoni. E-mail: wedalves@gmail.com

\section{Cidadania E Políticas Públicas no Contexto Do Programa de Educação Previdenciária - Pep}

\author{
Citizenship And Public Policies In The Context Of \\ The Preventive Education Program - PeP
}

\section{Guilherme Fernandes Magalhães* Wederson Marcos Alves**}

Como citar: MAGALHÃES, Guilherme Fernandes; ALVES, Wederson Marcos. Cidadania e políticas públicas no contexto do programa de educação previdenciária - PEP. Revista do Direito Público, Londrina, v. 14, n. 1, p. 10-25, abr. 2019. DOI: 10.5433/24157-108104-1.2019v14n1 p 10. ISSN: 1980-511X.

Resumo: O presente artigo é parte do trabalho de pesquisa desenvolvido dentro do programa de Mestrado Profissional em Tecnologia, Ambiente e Sociedade - TAS da Universidade Federal dos Vales do Mucuri e Jequitinhonha - UFVJM, que tem por objetivo investigar o Programa de Educação Previdenciária PEP, executado pelo Instituto Nacional do Seguro Social - INSS, como disseminador de informações dos direitos previdenciários. O tema ainda aborda esta política pública e seus reflexos para garantia da renda da população, suas implicações para a promoção da cidadania e os conceitos que emolduram o reconhecimento de direitos aos benefícios. Apresenta-se também, o contexto histórico e a evolução da Previdência Social no Brasil, bem como as garantias constitucionais do direito à informação e do princípio da publicidade na administração pública. $\mathrm{O}$ estudo ainda revela o quantitativo e as diferentes modalidades de ações educacionais, desenvolvidas pelo programa, relativo aos anos de 2015 a 2016, propondo um debate sobre a sua efetividade. Mesmo assim, verifica-se uma relevante carência de informações, da legislação previdenciária brasileira, por parte dos seus cidadãos, fator que o PEP procura solucionar.

Palavras-Chave: Políticas Públicas; Programa de Educação Previdenciária; Cidadania.

Abstract:This article is part of the research carried out within the Professional Master\&\#39;s Program in Technology, Environment and Society, of the Federal University of the Mucuri and 
Jequitinhonha Valleys - UFVJM, whose objective is to investigate the Social Security Education Program (PEP) By the National Institute of Social Security - INSS, as disseminator of information on social security rights. The theme also addresses this public policy and its reflexes for ensuring the income of the population, its implications for the promotion of citizenship and the concepts that frame the recognition of rights to benefits. It also presents the historical context and the evolution of Social Security in Brazil, as well as the constitutional guarantees of the right to information and the principle of publicity in public administration. The study also reveals the quantitative and the different modalities of educational actions, developed by the program, for the years 2015 to 2016, proposing a debate about their effectiveness. Even so, there is a relevant lack of information, of the Brazilian social security legislation, by its citizens, a factor that the PEP seeks to solve.

Keywords: Public Policies; Social Security Education Program; Citizenship 


\section{INTRODUÇÃO}

A vida em sociedade e as interações entre os seus componentes, pessoas, animais e objetos em geral, são repletos de incertezas e perigos que rondam o presente e o futuro trazendo preocupações aos trabalhadores. Nenhum cidadão quer ver sua família passar por desprovimentos, ou seja, que não possa garantir uma proteção material. Temor de doenças ou acidentes que levem à invalidez ou à morte, receio da velhice desamparada ou mesmo do desemprego, são fatores que fazem o dia a dia do trabalhador ainda mais estressante. Na prática, para uma pessoa desprotegida, ocorrências naturais como ter um filho e até mesmo o fato de envelhecer, podem se tornar uma caminhada bem mais atribulada, do que realmente era o desejável. Portanto, não basta apenas esperar o melhor do futuro, é preciso planejamento e prevenção.

É no período produtivo da vida que se deve tomar medidas para amenizar as dificuldades inesperadas, e assegurar uma terceira idade tranquila e digna. Pelo visto, tranquilidade e segurança são os desejos de qualquer comunidade, e a proteção do cidadão é acima de tudo um dever do Estado, uma missão constitucional, garantida pela seguridade social, onde pode-se destacar a Previdência Social.

O conceito de previdência que temos atualmente sofreu diversas alterações com o passar do tempo, sendo fruto de diversas iniciativas por parte de entes privados e pelo próprio Estado. Cada época marca a rotina de vida de um trabalhador, o que traz impactos em toda nação. Para fazer frente a essas mudanças, a Previdência Social brasileira se reinventou ao passar dos anos, mudando seu rol de segurados, ampliando sua estrutura de atendimento e ampliando sua cobertura.

Atualmente, as políticas públicas relacionadas à Previdência Social no Brasil, possuem um importante veículo de divulgação, o Programa de Educação Previdenciária - PEP, que administrado pelo INSS - Instituto Nacional do Seguro Social, autarquia responsável pela operacionalização do atendimento a toda população nacional, promovem palestras, encontros e cursos, com a finalidade de conscientizar a toda sociedade dos seus direitos aos benefícios.

\section{CONTEXTO HISTÓRICO DA PREVIDÊNCIA SOCIAL NO BRASIL}

No Brasil, segundo Souza (2002), a Previdência Social iniciou-se num regime privado com participação facultativa, fator característico de associações mutualistas que, posteriormente, sob a égide estatal, passou para regime de seguro social obrigatório, e que, por diversas vezes, sofreu mudanças no grau de cobertura, na quantidade e qualidade dos benefícios oferecidos, na sua legislação regimental, bem como na estrutura de atendimento.

Considerado um marco para o regime previdenciário no Brasil, a Lei Eloy Chaves, que na verdade se deu através do Decreto No 4.682 de 24 de janeiro de 1923, instituiu a previdência 
pública brasileira. O deputado federal que, posteriormente, teve reconhecido seu nome no batismo dessa norma jurídica, foi quem apresentou o projeto de lei à Câmara dos Deputados e discursou favoravelmente a sua aprovação, concluindo com os dizeres:

O homem não vive só para si e para hora fugaz, que é o momento de sua passagem pelo mundo. Ele projeta sua personalidade para o futuro, sobrevive a si próprio em seus filhos. Seus esforços, trabalho e aspirações devem também visar, no fim da áspera caminhada, o repouso, a tranquilidade. Os espinhos, as angústias, só são suportados com a esperança do prêmio final, seja este embora incerto e quase inatingido. O projeto vem satisfazer essas necessidades imperiosas da alma humana, criando as pensões para as famílias dos empregados de estrada de ferro e as aposentadorias para estes (SOUZA, 2002, p. 20).

Com o advento desta lei, originaram-se as Caixas de Aposentadorias e Pensões (CAP), em cada uma das empresas de estrada de ferro existentes no Brasil, favorecendo os empregados dessas organizações, conforme o descrito no Art. $1^{\circ}$ da Lei Eloy Chaves:

As CAPs deveriam dar quatro benefícios para manter a renda e a saúde da família de um trabalhador em caso de doença, incapacidade, velhice ou morte. O primeiro era a aposentadoria por invalidez e por tempo de serviço, (atualmente é denominada aposentadoria por tempo de contribuição) sendo que esta última era recebida pelo trabalhador quando chegava à idade de cinquenta anos, com um mínimo de trinta anos de serviço. O segundo benefício envolvia pensões aos dependentes de um empregado morto. O terceiro benefício consistia em cuidados de saúde na forma de serviços médicos e a vantagem de comprar remédios a preço reduzido. Finalmente, a lei estabelecia que a CAP competia pagar as despesas de funeral dos membros segurados. Em acréscimo aos quatro benefícios básicos, a lei rezava que depois de dez anos de serviço, o empregado só podia ser demitido por causa grave provada pelo empregador em processo administrativo formal (MALLOY, 1986, p. 49-50).

Ibrahim (2006), destaca que a Great Western do Brasil, que depois foi rebatizada de Estrada de Ferro Santos-Jundiaí e posteriormente de FEPASA, foi a primeira empresa do Brasil a criar uma caixa de aposentadoria e pensão. Já Souza (2002) informa que foi o ferroviário Bernardo Gonçalves o primeiro beneficiado da aposentadoria baseada na Lei Eloy Chaves.

Com o advento desta nova norma, viu-se a necessidade de criar um órgão do governo que fosse responsável por supervisionar as ações das CAPs. Sendo assim, em 30 de abril de 1923, criou-se o Conselho Nacional do Trabalho, através do decreto 16.027. Devido à ampliação da cobertura previdenciária, houve uma proliferação de CAPs. E já no ano de 1931, existia um total de 98 (noventa e oito) unidades.

O regime das Caixas de Aposentadorias e Pensões foi: $1^{\circ}$ ) em 1926 (Lei 5.109, de 20-12) estendido aos portuários e marítimos; $2^{\circ}$ ) em 1928 (Lei 5.485, de 30-06) estendido ao pessoal das empresas de serviços telegráficos e radiotelegráficos; $3^{\circ}$ ) em 1930 (Decreto $\mathrm{n}^{\mathrm{o}}$ 20.465, de 01-10) estendido aos empregados dos demais serviços públicos concedidos ou explorados pelo Poder Público (ALVIM, 2016, p. 17). 
Porém, a numerosa quantidade de CAPs, não refletiu em qualidade e houve diversos problemas. Pereira Netto (2002), relata que surgiram Caixas criadas sem o número mínimo de participantes que pudessem garantir a sustentabilidade ao longo prazo, legislação diversa e exclusiva para cada CAP, que dificultava a tomada de medidas uniformes, além de ainda coexistirem uma grande parte de trabalhadores que estavam desprotegidos, pois, as empresas ao qual laboravam, não possuíam esse sistema.

Foi devido às grandes dificuldades já citadas, que o Governo Federal adotou um novo programa de Previdência Social no Brasil, ao qual deu o nome de IAP - Instituto de Aposentadoria e Pensões. Tratava-se de uma autarquia federal, criada através de decreto presidencial, que na época oferecia a todos os trabalhadores do território brasileiro, a proteção previdenciária para determinadas categorias profissionais. Todeschini (2000, p. 47), afirma que "os institutos foram formados a partir dos setores mais organizados e estrategicamente mais importantes da economia, em sua ordem de importância."

O sistema foi elaborado cronologicamente, a saber: em junho de 1993 criou-se o Instituto dos Marítimos (IAPM); em maio de 1934, o Instituto dos Comerciários (IAPC); em julho de 1934, o Instituto dos Bancários (IAPB); e em agosto de 1937, o Instituto dos Trabalhadores na Indústria (IAPI), não implementado até 1938. Depois, em agosto de 1938, todas as CAPs dos trabalhadores de transporte e carga foram integradas num único instituto, o IAPTEC (MALLOY, 1986, p.75).

Segundo Pereira Neto (2002), mesmo com o expressivo avanço da proteção para a maioria dos trabalhadores urbanos, que estavam abrangidos pela criação dos Institutos de Aposentadorias e Pensões, alguns ficaram ainda desprotegidos, como no caso dos empregados domésticos, dos trabalhadores rurais e os autônomos.

Depois de idas e vindas, várias análises técnicas e políticas, vem o advento da Lei 3.087, de junho de 1960, que uniformizou a norma relativa às contribuições e prestações referentes aos IAPs, que eram apenas pautados pelos seus próprios regulamentos.

Em 1946 e 1947, mais de dezesseis projetos que buscavam alterações, mínimas ou substanciais, no sistema de previdência social, foram introduzidos na legislatura, mas a maioria não vingou. Por isso, em 17 de julho de 1947, outro projeto global de reforma do sistema foi apresentado pelo deputado federal Aluízio Alves. Este projeto de lei, que criava uma nova legislação (a Lei Orgânica da Previdência Social) tornou-se o ponto focal de um longo debate legislativo, e só depois de cinco reformulações substanciais e de centenas de emendas, finalmente foi aprovado em 1960 (MALLOY, 1986, p.97).

Contudo, em 1988, com a promulgação da Constituição Cidadã, foi instituída a seguridade social no Brasil, que traz no caput do artigo 194, (BRASIL, 2012, p. 115) "seguridade social compreende um conjunto integrado de ações de iniciativa dos poderes públicos e da sociedade, destinadas a assegurar os direitos relativos à saúde, à previdência e à assistência social”. 
Essa novidade trouxe ganhos consideráveis para a sociedade brasileira, pois, se antes havia apenas a proteção social para alguns nichos específicos de profissões e classes profissionais, agora o sistema torna-se plural e alcança todos os cidadãos, ou seja, o regime de previdência passa a ter ampla cobertura.

Para Calsavara (2001), o sistema é repartição simples, onde os benefícios atuais serão pagos pelas contribuições dos trabalhadores em atividade, que depois, receberão das contribuições de futuras gerações, provendo o que se intitula como solidariedade intra e intergeracional. Assim, a arrecadação atual é imediatamente utilizada para quitar os benefícios atuais e não há formação de reservas.

\section{CIDADANIA}

A Previdência Social atua na proteção dos riscos sociais presentes ao longo da vida dos cidadãos. Todavia, existe uma parcela da população que desconhece tais mecanismos de proteção e, devido à desinformação, permanece à margem da cobertura previdenciária, prejudicando as garantias sociais oferecidas pelo Estado, passo importante na construção de uma sociedade mais cidadã. Sendo assim, a promoção da cidadania tem sido um marco a ser alcançando por toda esfera governamental, uma vez que, os detentores dos direitos, estão a cada dia, mais ávidos pelos benefícios da legislação que os protege. Sarlet (2009), relata que cidadania é um processo, que começou no início da história da humanidade e que se faz presente, através do desenvolvimento do homem, do saber e da conquista de direitos sociais, civis, políticos e pelo alcance da dignidade.

Cidadania não é algo pronto e acabado, mas é aquilo que se constrói contínua e coletivamente. Assim, a cidadania é hoje questão importante para formação familiar, na educação, em diversas instituições, e está relacionada ao aperfeiçoamento de um modo de vida e um direito elementar atestado por nossa Constituição Federal. O preceito material decorre de serem os direitos fundamentais elementos que formam a constituição material, com decisões sobre a estrutura básica do Estado e da sociedade (SARLET, 2009, p. 74-75).

Então, a cidadania é precedida do conceito de cidadão e suas prerrogativas, conforme descreve Jaime Pinsky:

Afinal, o que é ser cidadão? Ser cidadão é ter direito à vida, à liberdade, à propriedade, à igualdade perante a lei: é, em resumo ter direitos civis. É também participar no destino da sociedade, votar, ser votado, ter direitos políticos. Os direitos civis e políticos não asseguram a democracia sem os direitos sociais, aqueles que garantem a participação do indivíduo na riqueza coletiva: o direito à educação, ao trabalho, ao salário justo, à saúde, a uma velhice tranquila (PINSKY, 2013, p. 09).

Pode-se concluir que, para o alcance da cidadania, o indivíduo precisa ter sua dignidade humana respeitada.

Esse plano existencial traz como paramento lógico, o fato de que para haver cidadão há 
que se ter em mente a figura da pessoa. A cidadania é um acréscimo à dimensão existencial. Não se pode ser cidadão se não é pessoa, se não lhe reconhecem os parâmetros próprios da dignidade humana. Segundo Dalmo Dallari:

A cidadania expressa um conjunto de direitos que dá à pessoa a possibilidade de participar ativamente da vida e do governo de seu povo. Quem não tem cidadania está marginalizado ou excluído da vida social e da tomada de decisões, ficando numa posição de inferioridade dentro do grupo social (DALLARI, 1998, p. 21).

Para Covre (1995), a prática da cidadania pode ser o caminho para a construção de uma sociedade melhor. Os avanços científicos e tecnológicos, não são suficientes para que a sociedade fique melhor, é preciso que haja justiça e igualdade social, é preciso que haja respeito à condição humana das pessoas. Para que essa realidade aconteça, é necessário que os cidadãos tenham consciência também das suas responsabilidades, pois, ele é parte de um organismo complexo e coletivo ao qual se dá o nome de nação. Sendo assim, o exercício da cidadania não fica restrito somente aos direitos, mas aos deveres e à participação política e da vida em comunidade ao qual está inserido.

Quando se atua em sociedade, verifica-se que no cotidiano, os indivíduos são ao mesmo tempo, matéria-prima e produto do que veem, aprendem, conversam e pensam. Essa reflexão remete ao papel desempenhado por cada um como um ser social, e também como ser humano, ao qual aborda Vazquez:

Fala-se algumas vezes da essência do homem ou "essência humana". Estão ali também as expressões "realidade humana" e "verdadeira realidade humana", que tem o mesmo conteúdo conceitual que o de "essência" ou "natureza" do homem. (SÁNCHEZ VÁZQUEZ, 2007, p. 401-402).

A essência humana "não é uma abstração inerente ao indivíduo singular. Em sua realidade ela é o conjunto das relações sociais" (MARX, 2007b, p28).

A sociedade, enquanto gênero coletivo de pessoas, vive realidades distintas quando a relacionamos ao tempo e ao espaço de convivência. Seus costumes, língua e cultura são diversas e mutantes, o que transforma o indivíduo que, ao mesmo tempo, transforma a sociedade e prepara, segundos os conhecimentos adquiridos, novas realidades e mudanças nos ambientes de vivência.

Esses aspectos são também tema de reflexão na obra intitulada $O$ Capital, em que Marx descreve que "o trabalho é uma necessidade natural e eterna de efetivar o intercâmbio material entre o homem e a natureza, e, portanto, de manter a vida humana" (MARX, 1985, p.50).

Desse modo, a sociedade é resultante das interações de diferentes épocas e gerações, alguns mais, outros menos contemporâneos, mas todos são afetados pelo tempo e pela convivência.

\section{O MECANISMO DE POLÍTICAS PÚBLICAS}


A ausência de informações e políticas públicas, com intuito de promover acesso aos direitos previdenciários, visando à proteção da vida e promoção da cidadania, é um desafio que transcende o período de um ou mais governos, perpassando gerações. Assim, é necessário estabelecer um pacto social consistente, que mobilize um mutirão nacional para viabilizar o sistema previdenciário frente aos desafios do futuro.

Segundo Souza (2006), o conceito de políticas públicas ganhou destaque nos últimos anos como área do conhecimento, o que elevou o patamar de observação das instituições, bem como das regras, elaboração, implementação, modelos que orientam a tomada de decisão e avaliação. Outra característica importante é a sobreposição da ótica governamental, em detrimento das políticas keynesianas ${ }^{1}$, tanto de ordem econômica quanto das sociais.

A mesma autora também afirma que, como disciplina acadêmica, as políticas públicas nascem por volta de 1950, como um subgrupo da ciência política nos Estados Unidos, através de um rompimento com as tradições europeias que focavam os estudos no Estado e suas instituições. Esse novo tratamento cognitivo é então destacado como a ação estatal que transforma a sociedade, segundo afirma Muller e Surel:

[...] a ação do Estado pode ser considerada como o lugar privilegiado em que as sociedades modernas, enquanto sociedades complexas, vão colocar o problema crucial de sua relação com o mundo através da construção de paradigmas ou de referenciais, sendo que este conjunto de matrizes cognitivas e normativas intelectuais determina, ao mesmo tempo, os instrumentos graças aos quais as sociedades agem sobre elas mesmas e os espaços de sentido no interior das quais os grupos sociais vão interagir (MULLER; SUREL, 2004, p.11).

Ferri Durá (2004), define política pública como sendo qualquer deliberação que traga inovação em sua essência, que é cercada de medidas que promovam sua execução e perpetuidade. $\mathrm{O}$ autor ainda chama atenção para uma característica intrínseca, o fato do processo de decisões ser permanente e em sequência. Nesse caso, o papel do gestor público no contexto social e nas instituições, são componentes que devem ser trabalhados de forma harmoniosa, para atender os anseios dos cidadãos.

A preponderância da ação gerencial envolve diversos fatores, dentre eles, o planejamento como um dos pilares, e a execução pelas lideranças políticas, nas instâncias do executivo municipal, estadual e federal. Contudo, as políticas públicas ainda apresentam algumas particularidades, conforme descreve Souza:

Apesar da aceitação de várias teses do "novo gerencialismo público" e da experimentação de delegação de poder para grupos sociais comunitários e/ou que representam grupos de interesse, os governos continuam tomando decisões

1 John Maynard Keynes (1883-1946) Criador da Teoria Macroeconômica, sendo considerado um dos mais importantes economistas do Século XX, defensor da intervenção do Estado na economia como geradora de demanda, mediante investimentos com vistas a garantir a geração de emprego. No Brasil, suas ideias vigoraram até os anos 80 (MENDES et al, 2012, p.44) 
sobre situações-problema e desenhando políticas para enfrentá-las, mesmo que delegando parte de sua responsabilidade, principalmente a de implementação, para outras instâncias, inclusive não-governamentais. Das diversas definições e modelos sobre políticas públicas, podemos extrair e sintetizar seus elementos principais:

A política pública permite distinguir entre o que o governo pretende fazer e o que, de fato, faz.

A política pública envolve vários atores e níveis de decisão, embora seja materializada através dos governos, e não necessariamente se restringe a participantes formais, já que os informais são também importantes.

A política pública é abrangente e não se limita a leis e regras.

A política pública é uma ação intencional, com objetivos a serem alcançados.

A política pública, embora tenha impactos no curto prazo, é uma política de longo prazo.

A política pública envolve processos subsequentes após sua decisão e proposição, ou seja, implica também implementação, execução e avaliação (SOUZA, 2006, p. 36-37).

Nesse sentido, alguns programas de governo, a exemplo do PEP, visam apresentar novas possibilidades de aumento da proteção social, através da educação e do processo de ensino com ações de orientação e informação, que se constituem como disseminadores externos para cooperação institucional. Visa-se utilizar o processo educacional como ferramenta para diminuição da desinformação e desconhecimento da legislação previdenciária, culminando na garantia e manutenção de direitos que justifiquem a formação de uma sociedade igualitária e mais cidadã.

A Tabela I traz números que identificam essa realidade e constatam o grau elevado do índice de indeferimento de benefícios, quando relacionados aos que foram solicitados. Ressaltase que esses dados fazem referência a todos os tipos de requerimentos (Auxílio-doença, Salário Maternidade, Aposentadorias, Pensão por Morte e Auxílio-reclusão), demandados por todos os tipos de segurados (empregados, desempregados, trabalhadores rurais, empregados domésticos, contribuintes individuais, trabalhadores avulsos e seus dependentes) e possui abrangência nacional.

É notório que examinando os elementos da Tabela I, pode-se inferir que no decorrer dos anos 2010 a 2015, o percentual de denegações de protocolos diminuiu 7,7\% ao passo que o número de benefícios mantidos ou ativos aumentaram, passando de 28,1 para 32,7 milhões. Mesmo não podendo transferir às ações do PEP, toda essa mudança de realidade, é fato que as ações empregadas pelo programa se consolidaram e certamente contribuíram para o alcance desses resultados. Conforme a Tabela II, somente no ano de 2015 foram capacitadas o total de 492.544 (quatrocentos e noventa e duas mil, quinhentos e quarenta e quatro) pessoas que participaram das ações do programa, e por consequência, tornaram-se disseminadores do conhecimento previdenciário, fazendo com que a repercussão dessa cultura pudesse alcançar números superiores ao que foi apresentado.

Essas observações desvelam uma característica positiva da instituição previdenciária brasileira, e demonstram o aspecto intrínseco do Programa de Educação Previdenciária em aumentar a propagação da política previdênciaria nacional. 


\begin{tabular}{|c|c|c|c|c|c|}
\hline$\underline{\text { Benefícios }}$ & $\underline{\text { Solicitados }}$ & $\underline{\underline{\text { Concedidos }}}$ & $\underline{\underline{\text { Indeferidos }}}$ & $\underline{\underline{\text { Mantidos }}}$ & $\begin{array}{c}\text { Razão entre benefícios } \\
\text { indeferidos e solicitados }\end{array}$ \\
\hline $\mathbf{2 0 1 0}$ & Quantidade* & Quantidade* & Quantidade* & Quantidade* & Percentual \\
\hline $\mathbf{2 0 1 1}$ & 7,8 & 4,6 & 3,2 & 28,1 & $41,03 \%$ \\
\hline $\mathbf{2 0 1 3}$ & 8,7 & 4,7 & 3,2 & 29,0 & $40,00 \%$ \\
\hline $\mathbf{2 0 1 4}$ & 8,6 & 5,2 & 3,3 & 31,1 & $37,93 \%$ \\
\hline $\mathbf{2 0 1 5}$ & 7,8 & 4,4 & 2,6 & 32,70 & $36,05 \%$ \\
\hline $\begin{array}{c}\text { Total } \\
\text { Geral }\end{array}$ & 40,9 & 24,1 & 15,4 & & $33,33 \%$ \\
\hline
\end{tabular}

Fonte: ANASPS - Associação Nacional dos Servidores Públicos da Previdência e da Seguridade Social - Grandes Números da Previdência Social - Dezembro de 2015. Total de Benefícios Atendidos no Brasil - 2010 a 2015. elaborada pelo autor. * Valores expressos em milhões

\section{A LEI DE ACESSO À INFORMAÇÃO E O PROGRAMA DE EDUCAÇÃo PREVIDENCIÁRIA}

Em se tratando de tema previdenciário e sua grande complexidade, observada em virtude das várias alterações e da quantidade de normas, acompanhar e operacionalizar os benefícios ofertados, torna-se um desafio para os cidadãos em geral e até mesmo para os profissionais que militam na área. Por isso, muitos dos segurados, que nem mesmo conhecem seus direitos, não o buscam, o que promove um enorme prejuízo social e econômico.

Esse aspecto revela a hipossuficiência sobre a legislação previdenciária e seus procedimentos. Contudo, é notório que o Estado, como promotor do bem-estar social e garantidor dos direitos e conquistas constantes na sua ordem normativa maior, ou seja, sua constituição, não pretende que tal fato ocorra ou possa continuar a ocorrer. Sendo assim, a norma jurídica brasileira, garante o acesso à informação de toda a legislação, bem como do arcabouço de benesses que o Estado coloca à disposição da nação, conforme os artigos $5^{\circ}$ e o $37^{\circ}$ da Constituição Federal:

Art $5^{\circ}$ - XXXIII - todos têm direito a receber dos órgãos públicos informações de seu interesse particular, ou de interesse coletivo ou geral, que serão prestadas no prazo da lei, sob pena de responsabilidade, ressalvadas aquelas cujo sigilo seja imprescindível à segurança da sociedade e do Estado.

Art. 37. A administração pública direta e indireta de qualquer dos Poderes da União, dos Estados, do Distrito Federal e dos Municípios obedecerá aos princípios de legalidade, impessoalidade, moralidade, publicidade e eficiência e, também, ao seguinte: $\S 3^{\circ} \mathrm{A}$ lei disciplinará as formas de participação do usuário na administração pública direta e indireta, regulando especialmente: II - o acesso dos usuários a registros administrativos 
e as informações sobre atos de governo, observado o disposto no art. $5^{\circ}$ - X e XXXIII (BRASIL - 2012, p. 14, 36-38).

Tal fato é observado por Nunes (2014) com um direito fundamental, advindo da democracia e do estado democrático de direito:

O Direito de Acesso à Informação é um Direito Fundamental explícito, que decorre das categorias Democracia, Estado Democrático de Direito e República: Sobre a Democracia substancial, examinou-se que faz parte de sua natureza ou fundamento, entre outros, o respeito e garantia aos Direitos Fundamentais (que são preliminares a ela e compõem a esfera do indecidível, ficando indisponíveis à vontade da maioria), a fixação de limites e vínculos ao poder estatal, as liberdades de consciência, expressão e de imprensa, a boa gestão dos assuntos públicos voltados ao interesse do povo e a possibilidade de Controle Social do Povo sobre os atos estatais. O Estado Democrático de Direito [...] tem como papel central a concretização da transformação social e política, com a participação da Sociedade, obrigando-o a resgatar as promessas não cumpridas da Democracia, com destaque à busca pelo fim da presença do poder invisível, fomentando a participação popular, que inclui o Controle Social, capaz de verificar se realmente se pratica uma boa administração em vista da transformação da realidade. [...]

A respeito da República constatou-se que é sua natureza a boa gestão, visando o bem comum, a vontade da maioria, com respeito aos Direitos Fundamentais e direitos das minorias, combatendo-se privilégios e discriminações (NUNES, 2014, p. 121-122).

Essas garantias vinculam o poder público de prover a todos sem distinção alguma, a igualdade de oportunidades quanto ao acesso dos benefícios e serviços prestados pela Previdência Social, e que, neste caso, é desempenhado pelo Programa de Educação Previdenciária - PEP.

A origem e fundamentação legal do PEP, que até setembro de 2003, denominava-se Programa de Estabilidade Social (PES), foi instituído pela Portaria Ministerial $n^{\circ} 1.671$, em 15 de fevereiro do ano de 2000 e reestruturado pelas Portarias GM n ${ }^{\circ} 409$, revogada pela Portaria $n^{\circ}$ 1.276/2003, que mudou a denominação do Programa de PES para PEP, coordenado pela Secretaria Executiva do Ministério da Previdência Social e executado pelo INSS. Com a aprovação da estrutura organizacional do Instituto Nacional do Seguro Social pelo Decreto ${ }^{\circ}$. 5.870, de 08 de agosto de 2006, o PEP deixou de fazer parte da estrutura do Ministério da Previdência Social e passou a compor a Diretoria de Atendimento do INSS. A Portaria GM n ${ }^{\circ}$ 514, publicada em 13 de dezembro de 2010, definiu a coordenação e execução do Programa pelo INSS. Nesse sentido, observa-se a intenção do ente governamental de se fazer cumprir a lei de acesso à informação que para Sales:

A comunicação pública, assim, não é somente dar conhecimento de que existem documentos disponíveis para quem quiser consultá-los, na internet ou na prateleira de determinado órgão estatal. Ela desempenha a função educativa, informativa e de orientação social. Orienta-se para os fins de interesse público 
previstos na Constituição, segundo a forma administrativa. Ela deve promover a conscientização, fomentar o debate, criar uma "cultura de transparência", fazer com que o brasileiro finalmente compreenda que a Administração é sua e de todos, tornar a participação não somente possível, mas interessante, buscando a linguagem e o formato que tenham melhores condições de atingir o público-alvo (SALES, 2014, p. 293).

Por isso, o objetivo do Programa de Educação Previdenciária (PEP) é informar e conscientizar a sociedade acerca de seus direitos e deveres em relação à Previdência Social e os meios de exercê-los, assegurando a proteção social aos cidadãos, por meio de sua inclusão e permanência no Regime Geral de Previdência Social, contribuindo para divulgação dos canais de atendimento e socialização de informações, demonstrando o compromisso da instituição com a sociedade e a sustentabilidade do país (BRASIL, 2014).

A exemplo disso, a Tabela II descreve seis ações educacionais promovidas pelo PEP em todo território nacional, no período de Janeiro de 2015 até Outubro de 2016; são eles: Cursos, Informações pela Internet, Mídia, Orientações e Informações, Palestras e Reuniões. Foram totalizados 9.242 (nove mil duzentos e quarenta e duas) ações que alcançaram 811.506 (oitocentos e onze mil, quinhentos e seis) expectadores, que passaram a conhecer melhor seus direitos e os serviços prestados pela Previdência Social.

\begin{tabular}{|c|c|c|c|c|c|c|c|c|c|c|c|c|c|c|}
\hline \multicolumn{15}{|c|}{ AÇÕES DO PEP } \\
\hline $\begin{array}{l}\frac{\text { Acões }}{\underline{\text { Ano }}} \\
\end{array}$ & \multicolumn{2}{|c|}{ Curso } & \multicolumn{2}{|c|}{$\begin{array}{l}\text { Informacão } \\
\text { Pela Internet }\end{array}$} & \multicolumn{2}{|c|}{ Mídia } & \multicolumn{2}{|c|}{$\begin{array}{c}\frac{\text { Orientacões }}{\mathrm{e}} \\
\text { Informacões }\end{array}$} & \multicolumn{2}{|c|}{ Palestra } & \multicolumn{2}{|c|}{$\underline{\text { Reunião }}$} & \multirow{2}{*}{$\frac{\underline{\text { Acões }}}{\text { TOTAL }}$} & \multirow{2}{*}{$\begin{array}{l}\text { Pessoas } \\
\text { TOTAL }\end{array}$} \\
\hline & Quant. & Pes., & Quant. & Pes., & Quant. & Pes., & Quant. & Pes., & Quant. & Pes., & Quant. & Pes., & & \\
\hline 2015 & 46 & 973 & 7 & 497 & 378 & 13324 & 1601 & 243779 & 3219 & 233910 & 208 & 60 & 5.459 & 492.544 \\
\hline 2016 & 30 & 450 & 14 & 2800 & 283 & 15697 & 1032 & 161469 & 2251 & 138545 & 172 & 1 & 3.783 & 318.962 \\
\hline $\begin{array}{l}\text { Total } \\
\text { Geral }\end{array}$ & 76 & 1423 & 21 & 3297 & 661 & 29021 & 2633 & 405248 & 5470 & 372455 & 380 & 60 & 9.242 & 811.506 \\
\hline
\end{tabular}

Fonte: SisGpep - Sistema de Gestão do Programa de Educação Previdenciária - Janeiro de 2015 a Outubro de 2016 - Tabela elaborada pelo autor.

Agora, esses cidadãos, que até então desconheciam as regras para concessão dos benefícios, foram informados e, com estas capacitações, passaram à condição de multiplicadores das informações previdenciárias e poderão impactar milhares de pessoas em todas as regiões do país.

\section{CONSIDERAÇÕES FINAIS}

Percebe-se que a carência de informação configura como um grande gargalo para a concessão dos benefícios previdenciários. Esse entrave ocorre no atendimento de parte da clientela previdenciária, a exemplo da população do meio rural que, na maioria das vezes, não consegue 
a conclusão do requerimento pretendido. Por consequência, ocorrem diversos desdobramentos: abertura de prazo para cumprimento de exigências e apresentação dos documentos complementares; diligências de pesquisas; abertura de prazo recursal nos casos de indeferimento; e até mesmo a provocação do poder judiciário, resultando em enorme dispêndio de recursos do poder governamental, além de prejudicar o segurado e sua família.

Isso só ocorre, pois, perdura por parte do grande público, várias dúvidas sobre as normas aplicadas aos casos concretos, leis que até mesmo já se encontram ultrapassadas, porém que são ainda interpretadas como vigentes.

Nesse contexto, o PEP é de fundamental importância para a inclusão social, pois promove a divulgação do conhecimento previdenciário, especialmente às pessoas que se encontram desprotegidas, possibilitando a essas, se inscreverem na Previdência Social, para assim, terem proteção previdenciária quanto aos eventos de doença, invalidez, morte e idade avançada.

Assim sendo, a proteção ao trabalhador é ampliada e as pessoas passam a exercer com mais dignidade seus direitos de cidadania, inserindo-se na sociedade como cidadãos participativos, uma vez que a proteção previdenciária também é condição para a inclusão social. Promover a inclusão dos trabalhadores e trabalhadoras no Sistema Previdenciário, divulgar políticas públicas e valorizar cidadania: esses são os compromissos do PEP (BRASIL, 2014).

O programa, por um lado, possui finalidade social pela inclusão de mais pessoas no sistema de Previdência Social, às quais são disponibilizados os conhecimentos necessários para o exercício de seus direitos e deveres. Por outro lado, o PEP visa contribuir com o desenvolvimento institucional do INSS, pela melhoria da qualidade do atendimento oferecido nas agências, mediante ações educacionais que favoreçam: a redução da demanda espontânea (demanda não agendada); o fortalecimento do atendimento agendado; a melhoria do fluxo operacional; a minimização dos impactos negativos sobre a intermediação de terceiros; o conhecimento por parte do cidadão, dos documentos de que precisa estar munido quando for reivindicar qualquer benefício.

As Tabelas I e II apresentam referências que impulsionam o debate sobre a efetividade do programa, e propõem sobre todos os aspectos, que as diversas modalidades de propalação da legislação seja um diferencial que repercute em todo meio social. O exemplo disso é certamente, o fenômeno da diminuição dos processos indeferidos face ao aumento dos benefícios mantidos.

O estabelecimento do programa evidencia uma iniciativa louvável de opção de política pública, contudo, seu alcance merece ser investigado. Seria o PEP suficientemente bom para promover a cidadania em tudo que se propõe? Qual a medida da sua abrangência? A capilaridade do seu alcance corresponde ao investimento financeiro destinado ao programa? São ainda questionamentos que merecem mais pesquisa e apuração.

O programa tem características vantajosas a serem consideradas, a saber, educar gerações, facilitar o reconhecimento de direitos constitucionais, o que irá gerar recursos econômicos e promover o bem-estar social. No entanto, o que se observa é que a população ainda carece de 
muita informação em relação à seguridade social, necessitando o desenvolvimento de novas ações e materiais que possam contribuir na melhoria da divulgação dos seus direitos, bem como a forma de alcançá-los.

\section{REFERÊNCIAS}

ALVIM, Ruy Carlos Machado. Citado por FERNANDES, Aníbal. Uma história crítica da legislação previdenciária Brasileira. RDT 18/13. Citado por PEREIRA JÚNIOR, Aécio. Evolução histórica da Previdência Social e os direitos fundamentais. Jus Navigandi, Teresina, ano 9, n. 707, 12 jun. 2005. Disponível em: < http://jus.com.br/revista/texto/6881 >. Acesso em: 07 fev. 2016

BRASIL. Constituição (1988). Constituição da República Federativa do Brasil: Texto constitucional promulgado em 5 de outubro de 1988. 35. ed. Brasília, DF: Senado Federal, Subsecretarias de Edições técnicas, 2012.

. Decreto n. 97.936, de 10 de julho de 1989. Institui o Cadastro Nacional do Trabalhador e dá outras providências. < http://www.planalto.gov.br/ccivil_03/ decreto/1980-1989/D97936.htm >. Acesso em 19 de Dezembro de 2015.

Grandes Números da Previdência Social - Dezembro de 2015. Publicado em 26 de fevereiro de 2016. ANASPS - Associação Nacional dos Servidores Públicos da Previdência e da Seguridade Social. < https://www.anasps.org.br/grandes-numeros-da-previdencia-socialdezembro2015/ >. Acesso em 09 de Março de 2017.

. Lei n 8.212, de 24 de julho de 1991. Dispõe sobre a organização da Seguridade Social, institui Plano de Custeio, e das outras providências. < http://www.planalto.gov.br/ ccivil_03/leis/18212cons.htm >. Acesso em 19 de Dezembro de 2015.

Social 2014.

. Manual do Programa de Educação Previdenciária. Instituto Nacional do Seguro

CALSAVARA, Rogério Pereira. A previdência social como fator de desenvolvimento socioeconômico dos municípios brasileiros. Monografia. Campinas: UNICAMP/

Instituto de Economia, 2001. Disponível em: < http://www.bibliotecadigital.unicamp.br/ document $/$ code $=000295442 \&$ opt $=3>$. Acesso em 02/06/ 2016.

COVRE, M. L. M. O que é cidadania?. São Paulo: Brasiliense, 1995.

DALLARI, Dalmo. Direitos Humanos e Cidadania. São Paulo: Moderna, 1998.

FERREIRA, A. B. de H. Dicionário da Língua Portuguesa. $1^{\mathrm{a}}$ ed. $15^{\mathrm{a}}$ impressão. Rio de Janeiro: Nova Fronteira, 1975.

FERRI DURÁ, J. Políticas Públicas. In REYES, R. (Dir.). Diccionario crítico de ciências socialis. Pub. Electrónica, Universidad Complutense, Madrid, 2004. Disponivel em: < http:// www.ucm.es/info/eurotheo/diccionario >. Acesso em: 07 setembro 2016.

IBRAHIM, Fábio Zambitte. Curso de direito previdênciário. 7. Ed. Rio de Janeiro: Impetus, 
2006.

MAlloy, James M. A política da Previdência Social no Brasil. Rio de Janeiro: Graal, 1986.

MARX, Karl. O capital: Crítica da Economia Política. Tradução Reginaldo Sant'Anna. São Paulo: DIFEL, 1985 b.

. Teses sobre Feuerbach. In: A ideologia alemã. Tradução Marcelo Backes. Rio de Janeiro: Civilização Brasileira, 2007b.

MENDES, Carlos Magno II...[et al.]. Introdução a Economia. Florianópolis: Departamento de Ciências da Administração/UFSC; [Brasília]: UAB, 2012.

MULLER, P.; SUREL, Y. A análise das políticas públicas. Pelotas: Educat, 2004.

NUNES, Alexandre Augusto Pereira. O Direito Fundamental de Acesso à Informação. Rio de Janeiro: Lumen Juris, 2014.

PEREIRA NETTO, Juliana Presotto. A previdência social em reforma: o desafio da inclusão de um maior número de trabalhadores. São Paulo: LTr, 2002.

PORTAL MPS. Programa de Educação Previdenciária. Disponível em: $<<$ http://www. previdencia.gov.br/acesso-a-informacao/programas-e-acoes/pep-programa-de-educacaoprevidenciaria/ > . Acesso em: 21 de Dezembro de 2015.

PINSKY, Jaime, Carla Bressanezi Pinsky, (orgs.). História da Cidadania. São Paulo: Contexto, 2013.

SALES, Ramiro Gonçalves. O Direito de Acesso à Pública Administrativa. Rio de Janeiro: Lumen Juris, 2014.

SARLET, Ingo Wolfgang. A Eficácia dos Direitos Fundamentais - Uma Teoria Geral dos Direitos Fundamentais na Perspectiva Constitucional. 10 ed. rev. atual. e ampl. Porto Alegre: Livraria do Advogado, 2009.

\section{SISTEMA DE GESTÃO DO PROGRAMA DE EDUCAÇÃO PREVIDENCIÁRIA -}

SISGPEP (2015-2017). Disponível em: $<$ http://acervo.ufvjm.edu.br/jspui/bitstream/1/1663/6/

guilherme_fernandes_magalhaes.pdf.txt $>$. Acesso em: 07 setembro 2016

SOUZA, Celina. Introdução Políticas Públicas: uma revisão da literatura. Porto Alegre, ano $8, n^{\circ} 16$, jul/dez 2006, p. 20-45.

SOUZA, Jorceli Pereira de et al. 80 anos de Previdência Social: a história da Previdência Social no Brasil - um levantamento bibliográfico documental e iconográfico. Brasília: MAPAS, 2002.

TODESCHINI, Remígio. Gestão da previdência pública e fundos de pensão: a participação da comunidade. São Paulo: LTr, 2000.

VÁZQUEZ, A. S. Ética. Rio de Janeiro: Civilização Brasileira, 2007. 
Como citar: MAGALHÃES, Guilherme Fernandes; ALVES, Wederson Marcos. Cidadania e políticas públicas no contexto do programa de educação previdenciária - PEP. Revista do Direito Público, Londrina, v. 14, n. 1, p. 10-25, abr. 2019. DOI: 10.5433/24157-108104-1.2019v14n1 p 10. ISSN: 1980-511X.

Recebido em: 16/03/2017.

Aprovado em: 29/08/2018. 